Military Technical College Kobry El-Kobbah, Cairo, Egypt

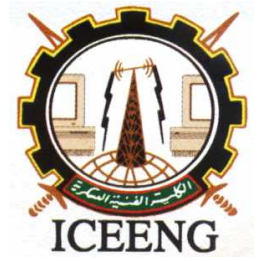

\title{
Predictive-adaptive controller based on fuzzy logic control tool
}

$$
\text { By }
$$

Mahdi M. El-Arini*

\author{
Zaghlol S. El-Razaz**
}

Ahmed M. Othman***

\section{Abstract:}

This paper presents an extremely innovated controller which depends on generating controller gains for the power system to enhance the stability of the system. The controller has more than one option to integrate the required task. Firstly it can be combined with load forecast program which out load duration curve to supply the controller with the predicated loading conditions to make the controller predictive.

The second, the controller is adaptive where it based on Fuzzy Logic (FL) algorithm to have all advantages of Artificial Intelligence (AI) in form of Fuzzy Logic (FL). The conventional programming control using optimal controller theory also is considered as stage inside the proposed controller to generate automatically the input-output patterns of fuzzy controller. The controller is applied on single machine system with wide range of machine modeling order and on multi-machine system to show the capability of the controller in enhancing the stability compared with the conventional controller.

\section{Keywords:}

Power system modeling, power system stabilizer, artificial intelligence, fuzzy logic algorithm, load forecasting and optimal control theory.

* Prof., Electrical Power and Machine Department, Zagazig University

** Prof., Electrical Power and Machine Department, Zagazig University

*** Assistant Lecturer, Electrical Power and Machine Dept., Zagazig University 


\section{Introduction:}

Power system stabilizers (PSS) have been widely used to enhance the system dynamic stability [1]-[12]. The basic function of a PSS is to produce an electrical torque component in phase with the rotor speed variation to add damping to the rotor oscillations by controlling its excitation using an auxiliary stabilizing signal. PSS design can be divided into two main procedures:

1) To select the location

2) To determine the parameter settings of all the PSSs.

Many approaches or indices based on open-loop system model have been proposed and successfully used for selecting the optimum PSS gains.

Power systems are complex nonlinear systems and often exhibit low-frequency power oscillations due to insufficient damping. Although the high gain, continuously acting automatic voltage regulators help to improve the dynamic limits of power systems, they also introduce negative damping and, consequently, make the system unstable, especially in large, weakly coupled systems. To overcome this problem, a supplementary stabilizing signal is introduced in the excitation system. Power System stabilizers provide this supplementary stabilizing signal and are widely used to suppress the generator electromechanical oscillations and enhance the over all stability of power systems. A conventional PSS (CPSS) is based on the use of a transfer Function designed for a linear model representing the generator at a certain operating point [11], [12]. CPSS are widely used and have improved the stability of power systems. However, because a CPSS is designed for a particular operating point for which the linearized transfer function model is obtained, it often does not provide satisfactory results over a wide range of operating conditions. Also the new trends of the control systems which based on Artificial Intelligence (AI) such as Artificial Neural Networks (ANN) and Fuzzy Logic (FL)...etc have an important role in improving system performance.

Sometimes the controller design tends to replace one of the machine supplementary devices such as AVR and/or PSS with AI controller and the design task is to find the value of the controller parameters which improve the system performance.

In recent years, new artificial intelligence-based approaches have been proposed to design adaptive PSS. These approaches include fuzzy logic (FL) [1], [4]-[7], neural networks (NN) [3] and genetic algorithm (GA) [2]. Fuzzy control appears to be suitable controller due to its low computational burden and ease of implementation using a microcomputer.

Fuzzy logic-based PSS (FLPSS) shows great potential in increasing the damping of generator oscillations, especially when made adaptive. In the proposed controller in this paper, the processing of the controller is different 
from the usual controllers where the eigen values of the system which summarize all model parameters and loading conditions are used as the inputs of fuzzy controller and the output will be the controller gains from the states to $\Delta$ Efd which added to system to enhance the stability to act as controller over the system. The controller program can linked with the load forecast program (which out the load duration conditions to make the controller predictive (or online)

\section{System Modeling}

\section{- Single-machine Infinite-bus System}

Consider a system shown in Fig.1 where a synchronous machine is connected to an infinite bus through a transmission line having resistance $R_{e}$ and inductance $^{X_{e}}$, the magnitude of the rms phase voltage of the infinite bus is $V_{\infty}$ with angle $\alpha$ w.r.t reference axis.

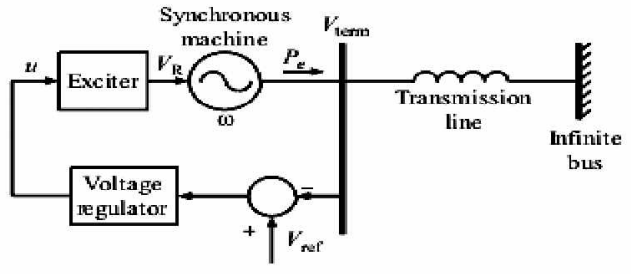

Fig. 1. Single-machine infinite-bus system.

The model of the system matrix is given as follows, where The state space form of the machine can be represented as

$\alpha=A x+B u$

Where the states of system are $x^{t}=\left[\begin{array}{lllllll}i_{d} & i_{F} & i_{D} & i_{q} & i_{Q} & \omega & \delta\end{array}\right]$ and the inputs $\operatorname{are} T_{m}$ and $v_{F}$. Where id the direct-axis armature current, $\mathrm{i}_{\mathrm{F}}$ the Field current, iq the quadrature-axis armature current, $\mathrm{i}_{\mathrm{D}}$ the direct-axis damper current, $\mathrm{i}_{\mathrm{Q}}$ the quadratureaxis damper current, $\omega$ rotor speed deviation, $\delta$ rotor angle. It is shown that when the system is subjected to small impacts, it tends to acquire a new operating state. During the transition between the initial state and the new state the system behavior is oscillatory. The initial state may be considered as a quiescent operating condition for the system. To examine the behavior of the system when it is perturbed such the new and the old equilibrium stated are nearly equal, the system equations are linearized about the quiescent operating condition. Using the linearization theory and considering the state space vector $\mathrm{x}$ has an initial states $\mathrm{xo}$ at $\mathrm{t}=\mathrm{to}$

$$
x_{o}^{\prime}=\left[\begin{array}{llllllll}
i_{d o} & i_{F o} & i_{D o} & i_{q o} & i_{Q o} & \omega_{o} & \delta_{o}
\end{array}\right] \text { One can get the model of the system given in }
$$

fig. (1) as follows 


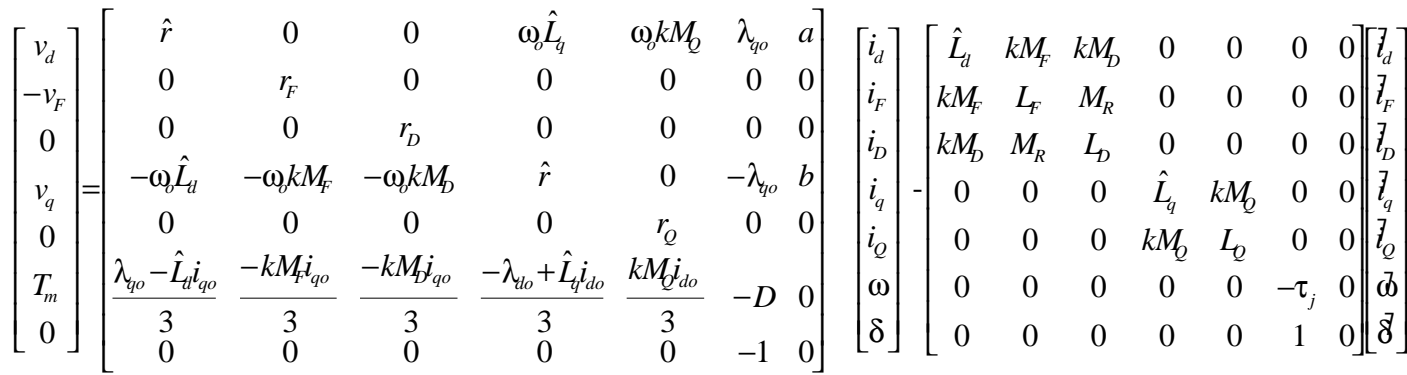

$$
\begin{aligned}
& a=-\sqrt{3} \cos \left(\delta_{o}-\alpha\right), b=-\sqrt{3} \sin \left(\delta_{o}-\alpha\right)
\end{aligned}
$$

Or in form $V=-K x-M \&$ which can rearranged to get the state space form

$\&=-M^{-1} K x-M^{-1} V=A x+B u$

where $A=-M^{-1} K$

The simplified third order model can be obtained using more assumptions as:

B Damper windings effect is neglected.

B Stator winding resistance is neglected.

B Balanced conditions are assumed.

\subsection{Multi-Machine System}

Higher Order Multi-Machine Models can be constructed. Firstly, a complex notation for machine $\mathrm{i}$ is defined as follows

$$
v_{i}=v_{q i}+j v_{d i} \quad i_{i}=i_{q i}+j i_{d i}
$$

Where the q-axis is taken as the phasor reference for each machine, which means that different voltages and currents are expressed in terms of different reference frames.

Consider the same system which has $\mathrm{n}$ machines and $\mathrm{r}$ loads except that the machines not represented in classical model.

Since the loads are represented as constant impedance, the system has only $\mathrm{n}$ active nodes. Using the network reduction (reduced Y-bus matrix).

The equations of the system are expressed in the d-q frame of reference of any machine, it desirable to express the various quantities to common reference frame moving at synchronous speed.

Now, one can combine the related equations to write the model of multi-machine system where also there are some algebraic equations which express the $\Delta V_{d}, \Delta V_{q}, \Delta V_{D}, \Delta V_{Q}, \Delta T_{e}$ which related to them selves and to the states as described in

full details in pervious sections. These algebraic equations also are linkers between the machines to construct the multi-machine model.

It is difficult to write the state space equations in normal separated form, so one can combine the equations to get

$P\left[\begin{array}{l}\dot{d} \\ y\end{array}\right]=Q[x]+R[u]$

Where $\mathrm{P}, \mathrm{Q}, \mathrm{R}$ are real constant matrices depending on system parameters and operating conditions. Then one can analyze this form to get 


$$
\left[\begin{array}{l}
A \\
\mathrm{~L} \\
C
\end{array}\right]=P^{-1} Q \quad \text { and } \quad\left[\begin{array}{c}
B \\
\mathrm{~L} \\
D
\end{array}\right]=P^{-1} R
$$

For example let a study case has a system contains three generators can be modeled with third order model in addition to static exciter states. The state variables of the system are: $\left(\Delta E_{q 1}^{\prime}, \Delta \omega_{1}, \Delta \delta_{1}, \Delta E_{f d 1}, \Delta v_{f 1}, \Delta E_{q 2}^{\prime}, \Delta \omega_{2}, \Delta \delta_{2}, \Delta E_{f d 2}, \Delta v_{f 2}, \Delta E_{q 3}^{\prime}, \Delta \omega_{3}, \Delta \delta_{3} \Delta E_{f d 3}, \Delta v_{f 3}\right)$

The matrix $\mathrm{P}$ and $\mathrm{Q}$ can be partitioned as $P=\left[\begin{array}{cc}P_{1} & P_{2} \\ P_{3} & P_{4}\end{array}\right] \quad$ and $\quad Q=\left[\begin{array}{c}Q_{1} \\ Q_{2}\end{array}\right]$

Where the dimension of $\mathrm{P}$ matrix $(\mathrm{m} \mathrm{x} \mathrm{m})$ where $\mathrm{m}$ is no. of the states and algebraic variables. P1 a unit matrix, P3 is a null matrix.

\section{PERFORMANCE CRITERIA}

The system eigen values is obtained from $\quad \operatorname{det}(A-\lambda \mathrm{I})=0$

The real part of Eigen values gives the damping rate where negative real part represent a damped oscillation and positive real part represent oscillation of increased amplitude and the imaginary of the eigen values gives oscillation frequency .

Mode identification is required to relate each eigen value by its related state variable, this is important to figure which state variables contribute largely in the system instability by having the least real part of the system eigen values.

Since system eigen values are functions of all control and design parameter, change in any of these parameters affect the system performance, and hence, causes a corresponding change in the eigen value related to it. This is used to identify the modes, by changing a parameter in a certain state equation and notice the change in the system eigen values. One that changed greatly is the one corresponding to this state equation, hence to the state variable of it. Changing the parameters of the differential equations to identify the modes is a simple way but it is suitable for small system, for large systems, mode identification is done by evaluating the participation matrix.

Where each raw of the participation matrix represent the state variables where the columns represent the eigen values and how this state participate in the eigen values. Since the system states time domain solution is a linear combination of system modes, so if one mode is unstable then all response of the system under disturbance will be unstable.

\section{PROPOSED CONTROLLER}

Fuzzy Logic theory will be used to construct system controller by calculating the suitable gains for any system parameters and operating conditions. The operating conditions and the system parameters can be summarized in the A-matrix where the elements of A-matrix are functions of them, so the eigen values are snap shots of system state and varied with each performance of system, also one scale for system stability is the real part of eigen values where for stable system they all should be in left hand side. Therefore, the inputs of the fuzzy controller will be the eigen values of 
the present performance of system and the outputs will be the controller gains which will improve the stability of the performance when applied on system.

The controller is predictive from loading conditions and system parameters to calculate the controller gains which added to the system to keep the stability of the system, this controller can combined with load forecast program to integrate the task, this shown in Fig. 4

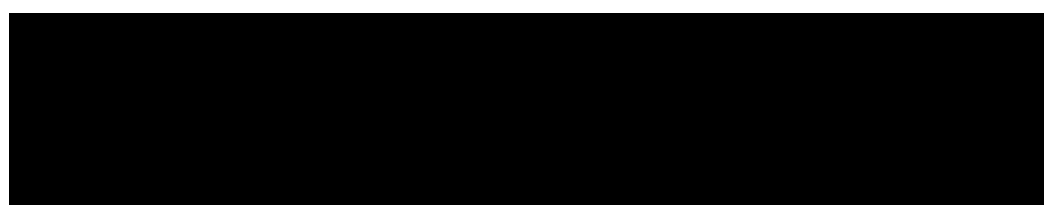

Fig. 4 Main Layout of Fuzzy Controller

The input of the fuzzy controller can be summarized in the following table (1) where the inputs of the fuzzy controller will be the eigen values which will varied according the model order.

Table (1) Classification of Fuzzy inputs

\begin{tabular}{|c|c|c|c|}
\hline & $\mathrm{M} / \mathrm{C}$ model & Exciter & Governor \\
\hline $\begin{array}{c}\text { 3rd } \\
\text { Order }\end{array}$ & $\begin{array}{l}\lambda 1=\Delta \delta \\
\lambda 2=\Delta \omega \\
\lambda 3=\Delta \mathrm{Eq}\end{array}$ & $\begin{array}{l}\lambda 4=\Delta \mathrm{V} 1 \\
\lambda 5=\Delta \mathrm{V} 2 \\
\lambda 6=\Delta \mathrm{Vr} \\
\lambda 7=\Delta \mathrm{Efd}\end{array}$ & $\lambda 8=\Delta \mathrm{Pm}$ \\
\hline $\begin{array}{l}\text { 5th } \\
\text { Order }\end{array}$ & $\begin{array}{l}\lambda 1=\Delta \delta \\
\lambda 2=\Delta \omega \\
\lambda 3=\Delta \mathrm{Id} \\
\lambda 4=\Delta \mathrm{Iq} \\
\lambda 5=\Delta \mathrm{If}\end{array}$ & $\begin{array}{l}\lambda 6=\Delta \mathrm{V} 1 \\
\lambda 7=\Delta \mathrm{V} 2 \\
\lambda 8=\Delta \mathrm{Vr} \\
\lambda 9=\Delta \mathrm{Efd}\end{array}$ & $\begin{array}{l}\lambda 10= \\
\Delta \mathrm{Pm}\end{array}$ \\
\hline $\begin{array}{c}\text { 7th } \\
\text { Order }\end{array}$ & $\begin{array}{l}\lambda 1=\Delta \delta \\
\lambda 2=\Delta \omega \\
\lambda 3=\Delta \mathrm{Id} \\
\lambda 4=\Delta \mathrm{Iq} \\
\lambda 5=\Delta \mathrm{If} \\
\lambda 6=\Delta \mathrm{ID} \\
\lambda 7=\Delta \mathrm{IQ}\end{array}$ & $\begin{array}{l}\lambda 8=\Delta \mathrm{V} 1 \\
\lambda 9=\Delta \mathrm{V} 2 \\
\lambda 10=\Delta \mathrm{Vr} \\
\lambda 11=\Delta \mathrm{Efd}\end{array}$ & $\begin{array}{l}\lambda 12= \\
\Delta \mathrm{Pm}\end{array}$ \\
\hline
\end{tabular}

On other side the outputs of the fuzzy controller can be the controller feed back gains for mechanical modes which affect strongly on system stability, which also summarized in the following table (2) 
Table (2) Classification of Fuzzy outputs

\begin{tabular}{|c|c|c|c|}
\hline & $\mathrm{M} / \mathrm{C}$ model & Exciter & Governor \\
\hline \multirow[t]{2}{*}{$\begin{array}{c}\text { 3rd } \\
\text { Order }\end{array}$} & $\begin{array}{r}\mathrm{K} 1 \text { to } \Delta \delta \\
\mathrm{K} 2 \text { to } \Delta \omega \\
\mathrm{K} 3 \text { to } \Delta \mathrm{Eq}\end{array}$ & $\begin{array}{l}\mathrm{K} 4 \text { to } \Delta \mathrm{V} 1 \\
\mathrm{~K} 5 \text { to } \Delta \mathrm{V} 2 \\
\mathrm{~K} 6 \text { to } \Delta \mathrm{Vr} \\
\mathrm{K} 7 \text { to } \Delta \mathrm{Efd}\end{array}$ & $\begin{array}{l}\mathrm{K} 8 \text { to } \\
\Delta \mathrm{Pm}\end{array}$ \\
\hline & \multicolumn{3}{|c|}{ Sub-optimal = K1, K2, K3 } \\
\hline \multirow[t]{2}{*}{$\begin{array}{l}5 \text { th } \\
\text { Order }\end{array}$} & $\begin{array}{l}\mathrm{K} 1 \text { to } \Delta \delta \\
\mathrm{K} 2 \text { to } \Delta \omega \\
\mathrm{K} 3 \text { to } \Delta \mathrm{Id} \\
\mathrm{K} 4 \text { to } \Delta \mathrm{Iq} \\
\mathrm{K} 5 \text { to } \Delta \mathrm{If}\end{array}$ & $\begin{array}{l}\mathrm{K} 6 \text { to } \Delta \mathrm{V} 1 \\
\mathrm{~K} 7 \text { to } \Delta \mathrm{V} 2 \\
\mathrm{~K} 8 \text { to } \Delta \mathrm{Vr} \\
\mathrm{K} 9 \text { to } \Delta \mathrm{Efd}\end{array}$ & $\begin{array}{l}\mathrm{K} 10 \text { to } \\
\Delta \mathrm{Pm}\end{array}$ \\
\hline & \multicolumn{3}{|c|}{ Sub-optimal = K1 , K2, K3 } \\
\hline \multirow[t]{2}{*}{$\begin{array}{c}\text { 7th } \\
\text { Order }\end{array}$} & $\begin{array}{l}\mathrm{K} 1 \text { to } \Delta \delta \\
\mathrm{K} 2 \text { to } \Delta \omega \\
\mathrm{K} 3 \text { to } \Delta \mathrm{Id} \\
\mathrm{K} 4 \text { to } \Delta \mathrm{Iq} \\
\mathrm{K} 5 \text { to } \Delta \mathrm{If} \\
\mathrm{K} 6 \text { to } \Delta \mathrm{ID} \\
\mathrm{K} 7 \text { to } \Delta \mathrm{IQ}\end{array}$ & $\begin{array}{l}\mathrm{K} 8 \text { to } \Delta \mathrm{V} 1 \\
\mathrm{~K} 9 \text { to } \Delta \mathrm{V} 2 \\
\mathrm{~K} 10 \text { to } \Delta \mathrm{Vr} \\
\mathrm{K} 11 \text { to } \Delta \mathrm{Efd}\end{array}$ & $\begin{array}{c}\mathrm{K} 12 \text { to } \\
\Delta \mathrm{Pm}\end{array}$ \\
\hline & Sub-c & $\mathrm{al}=\mathrm{K} 1$ & K3 \\
\hline
\end{tabular}

\subsection{Redesign of Fuzzy Controller}

The design of the proposed controller can be redesigned according to the inputs to the controller. Where instead of using all the eign values of the system, one can use the most effective eigen values which can be obtained from participation matrix analysis. The effect of using the effective eigen values only as inputs of the fuzzy controller is the simplicity of the overall design of fuzzy controller where the efforts exerted in selection the numbers and types of membership functions for effective eigen values are less than the efforts exerted in selection the numbers and types of membership functions for all eigen values. Where the main disadvantages of this design, that any one of the artificial intelligence tools as neural networks, fuzzy logic may confused if the amount of data not enough or the data hasn't certain clear classifications where the concept of using all the eigen values need more efforts but doesn't make the fuzzy controller confused where it separate and classes each patterns. So using the whole numbers of the eigen values is necessary for adapting the controller on fuzzy technique not for any complexity or not for certain stability criteria, where both the fuzzy controller gives the same results and the same response. 


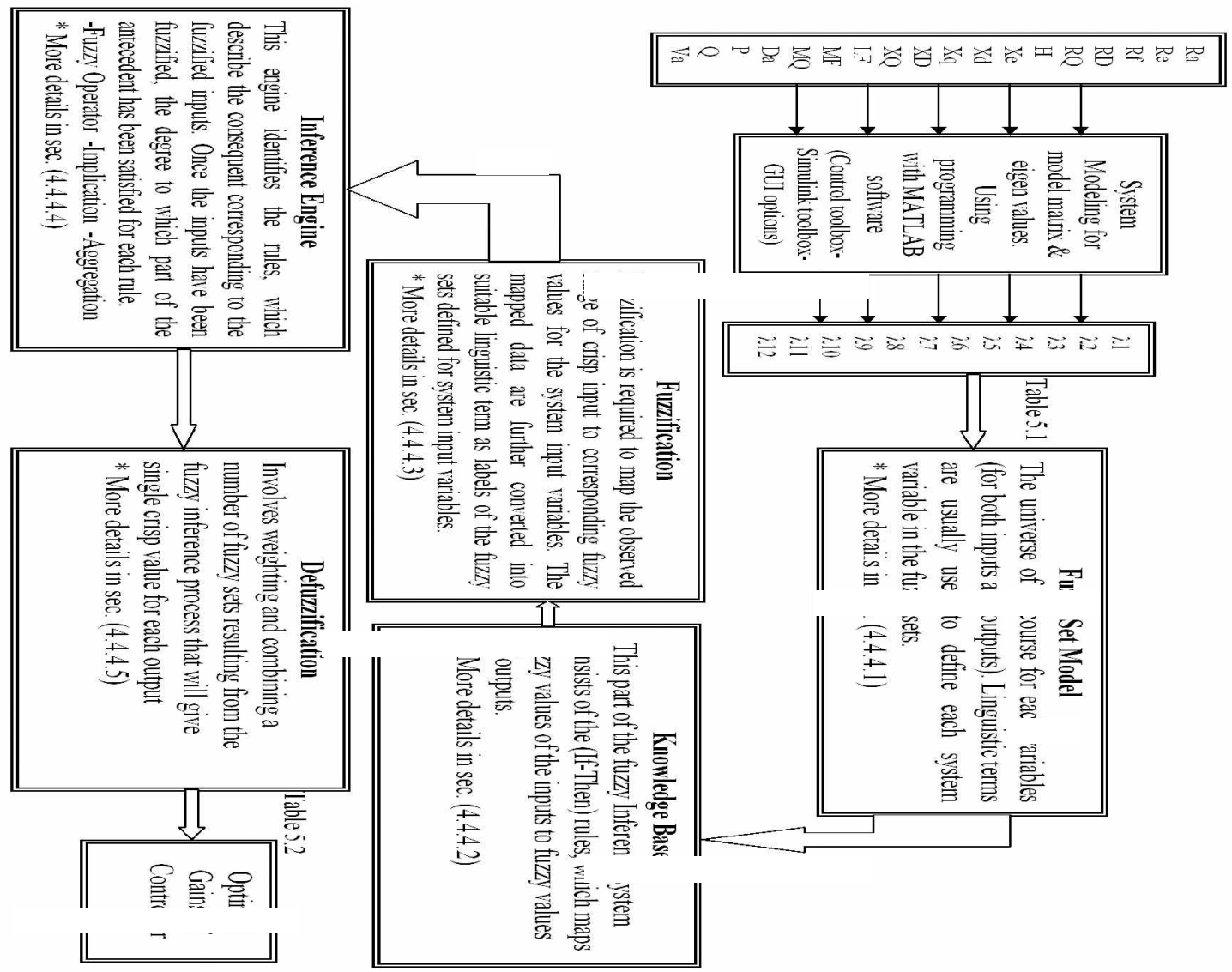

The numbers and types of inputs doesn't change the outputs response or output gains, they only change the design of the fuzzy controller and the numbers of membership functions and the numbers of rules where the fuzzy algorithm depend on mapping between inputs and outputs to reach the same task, so when we change the inputs, we change the spatial map of the system which mean change the method of show of data to fuzzy program in another mean, the change in the learning method of fuzzy how to get the outputs where it can learn the same information by more than one method.

\subsection{Fuzzy Controller for 3rd Model}

The inputs of fuzzy controller will be the eigen values of the system which summarize all model parameters and loading conditions and the output will be the optimal feed back gains from $\left(\Delta \omega, \Delta \delta, \Delta \mathrm{Eq}^{\prime}\right)$ to $\Delta \mathrm{Efd}$ which added to system to enhance the stability to act as controller over system.

Different operating and loading conditions are used in collecting the patterns which used in construct the fuzzy rules, also different model parameter values (as machine resistance, transmission resistance, machine inertia,...) are used to cover wide range to make the fuzzy controller generalized and has the ability to be efficient over wide operating conditions. While designing the fuzzy controller, the membership functions 
can be chosen according designer view to achieve the required task. Here we will use the Gaussian membership function to represent the input-output patterns because it has more than one advantage where it more smooth in its variations, also more suitable to deal with the non-linear patterns. The numbers of member functions will varied according the variable range and variable range also the clustering of variable values in certain region, also the parameters of each member function is adapted according data. After designing the fuzzy controller, we should test it on seen and unseen data to check the validation of controller. The number of each variable membership function is indicated in table 3

Table (3)

\begin{tabular}{|l|l|l|l|l|l|l|l|l|l|l||}
\hline $\boldsymbol{\lambda}_{\mathbf{1}}$ & $\boldsymbol{\lambda}_{\mathbf{2}}$ & $\boldsymbol{\lambda}_{\mathbf{3}}$ & $\boldsymbol{\lambda}_{\mathbf{4}}$ & $\boldsymbol{\lambda}_{\mathbf{5}}$ & $\boldsymbol{\lambda}_{\mathbf{6}}$ & $\boldsymbol{\lambda}_{\mathbf{7}}$ & $\boldsymbol{\lambda}_{\mathbf{8}}$ & $\mathbf{K}_{\mathbf{1}}$ & $\mathbf{K}_{\mathbf{2}}$ & $\mathbf{K}_{\mathbf{3}}$ \\
\hline \hline 30 & 22 & 14 & 12 & 19 & 18 & 18 & 13 & 18 & 15 & 14 \\
\hline
\end{tabular}

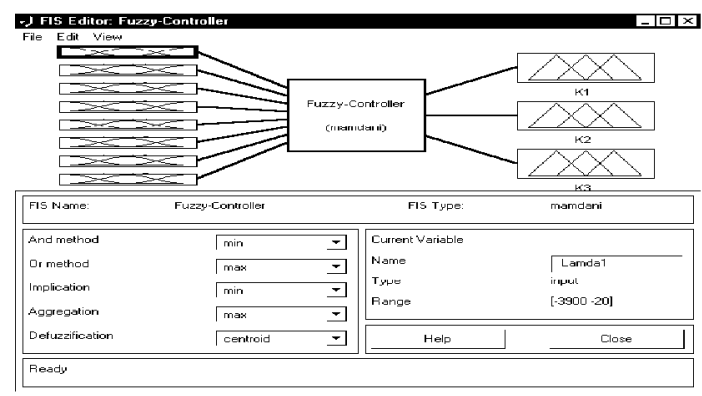

Fig. 6 Main Structure of 3rd order Model Fuzzy Controller

\subsection{Fuzzy Controller for 7 th Model}

The number of each variable membership functions is indicated in table 4 Table (4)

\begin{tabular}{|l|l|l|l|l|l|l|l|l|l|l|l|l|l|l|}
\hline \hline$\lambda_{1}$ & $\lambda_{2}$ & $\lambda_{3}$ & $\lambda_{4}$ & $\lambda_{5}$ & $\lambda_{6}$ & $\lambda_{7}$ & $\lambda_{8}$ & $\lambda_{9}$ & $\lambda_{10}$ & $\lambda_{11}$ & $\lambda_{12}$ & $\mathrm{~K}_{1}$ & $\mathrm{~K}_{2}$ & $\mathrm{~K}_{3}$ \\
\hline \hline 15 & 26 & 24 & 11 & 24 & 23 & 26 & 27 & 25 & 30 & 31 & 19 & 32 & 29 & 30 \\
\hline
\end{tabular}

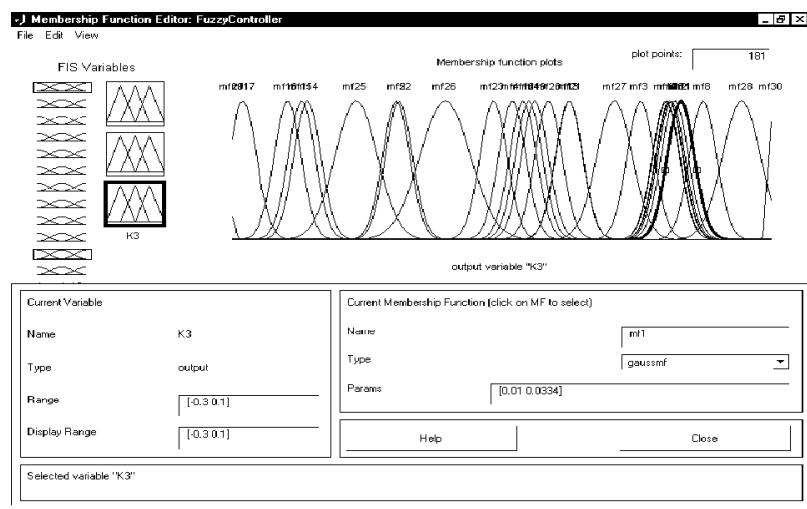

Fig. 7 Membership Functions of Output (3) of Fuzzy Controller 


\section{STUDY CASES}

\subsection{Comparison between Conventional and Fuzzy Controllers on 3rd Model}

Base case data with $p=1.3$ p.u

\begin{tabular}{||c|c|c||}
\hline \multicolumn{3}{|c|}{ Eigen value } \\
\hline Without controller & Conventional controller & Fuzzy controller \\
\hline$-1876.5+1982.5 \mathrm{i}$ & $-1879.5+1982.5 \mathrm{i}$ & $-2654+588.6 \mathrm{i}$ \\
$-1876.5-1982.5 \mathrm{i}$ & $-1879.5-1982.5 \mathrm{i}$ & $-2654-588.6 \mathrm{i}$ \\
-217.98 & -220.98 & -800.24 \\
-104.41 & -107.41 & -220.83 \\
$-1.7022+14.546 \mathrm{i}$ & -22.036 & -99.67 \\
$-1.7022-14.546 \mathrm{i}$ & $-4.7022+14.546 \mathrm{i}$ & -19.407 \\
-19.036 & $-4.7022-14.546 \mathrm{i}$ & -2.409 \\
-1.3982 & -4.3982 & -1.3986 \\
\hline
\end{tabular}

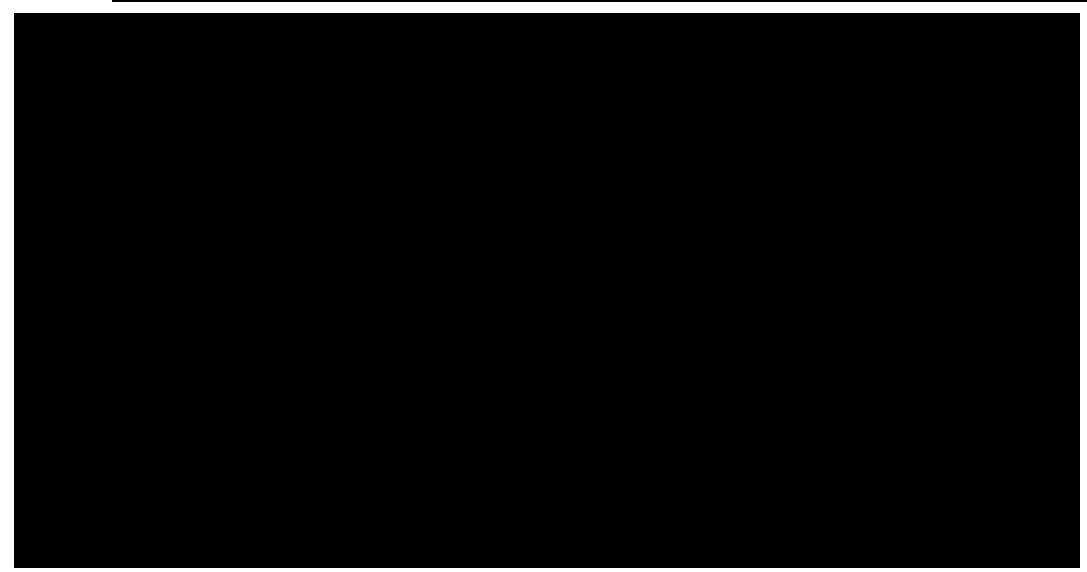

Fig. 8 -a,b Step Response of Speed Deviation for with $\Delta$ Vref $=10 \%$

\subsection{Comparison between Conventional and Fuzzy Controllers on $7^{\text {th }}$ Model}

Base case data with $p=2$ p.u

\begin{tabular}{||c|c|c||}
\hline \multicolumn{3}{|c||}{ Eigen value } \\
\hline Without controller & $\begin{array}{c}\text { Conventional } \\
\text { controller }\end{array}$ & Fuzzy controller \\
\hline-3768.2 & -3769.2 & -5330.3 \\
$-19.854+376.02 \mathrm{i}$ & $-20.854+376.02 \mathrm{i}$ & -800.25 \\
$-19.854-376.02 \mathrm{i}$ & $-20.854-376.02 \mathrm{i}$ & $-19.872+376.02 \mathrm{i}$ \\
-99.999 & -101 & $-19.872-376.02 \mathrm{i}$ \\
-46.567 & -47.567 & -100 \\
-36.891 & -37.891 & -37.267 \\
-20.774 & -21.774 & -45.503 \\
$-2.0417+7.59 \mathrm{i}$ & $-3.0417+7.59 \mathrm{i}$ & $-2.9431+9.6504 \mathrm{i}$ \\
$-2.0417-7.59 \mathrm{i}$ & $-3.0417-7.59 \mathrm{i}$ & $-2.9431-9.6504 \mathrm{i}$ \\
$0.74824+3.6325 \mathrm{i}$ & $-0.25176+3.6325 \mathrm{i}$ & -0.52338 \\
$0.74824-3.6325 \mathrm{i}$ & $-0.25176-3.6325 \mathrm{i}$ & -2.0235 \\
-1.3982 & -2.3982 & -1.3986 \\
\hline
\end{tabular}




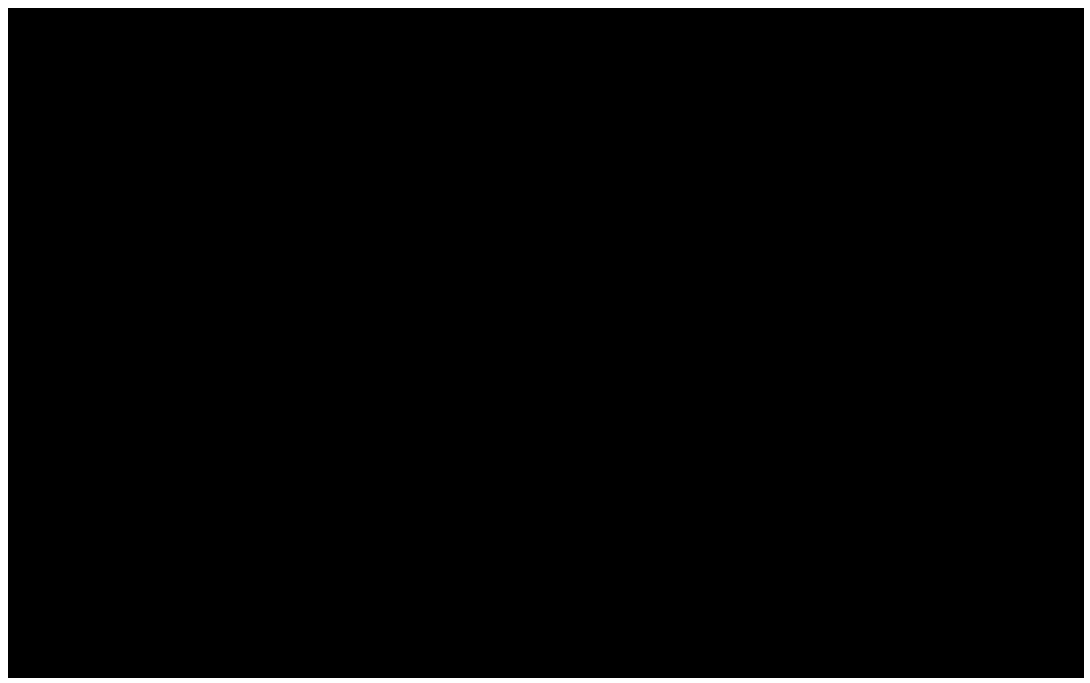

Fig. 9 -a,b Step Response of Speed Deviation for with $\Delta$ Vref $=10 \%$

\subsection{Case Study: Modeling of Multi-Machine System}

The study case is 9-bus system. There are three generator and six load buses with system configuration as shown in fig. 10. Data from IEEE [11].

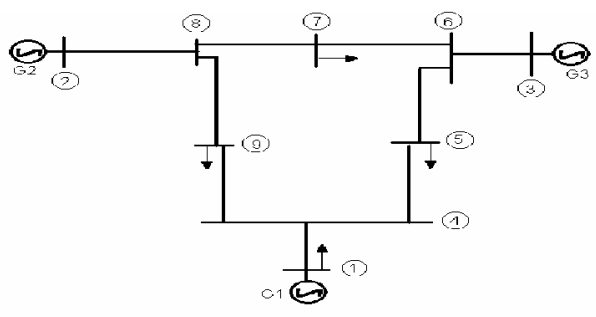

Fig. 10 Multi-Machine System

\subsection{Fuzzy Controller on Multi-Machine System}

The fuzzy controller is central controller sub-optimal technique where it receive the eigen values of original system which is required to enhance its stability and calculate the controller gains of mechanical states of units.

The number of each variable membership functions for Multi-Machine Fuzzy Controller is indicated in following table 


\begin{tabular}{|c|c|c|c|c|c|c|c|c|c|c|c|c|c|c|}
\hline$\lambda_{1}$ & $\lambda_{2}$ & $\lambda_{3}$ & $\lambda_{4}$ & $\lambda_{5}$ & $\lambda_{6}$ & $\lambda_{7}$ & $\lambda_{8}$ & $\lambda_{9}$ & $\lambda_{10}$ & $\lambda_{11}$ & $\lambda_{12}$ & $\lambda_{13}$ & $\lambda_{14}$ & $\lambda_{15}$ \\
\hline 32 & 38 & 15 & 40 & 40 & 36 & 36 & 37 & 36 & 41 & 40 & 38 & 40 & 24 & 25 \\
\hline & $\mathrm{K}_{1}$ & & $\mathrm{~K}_{2}$ & & $\mathrm{~K}_{3}$ & & $\mathrm{~K}_{4}$ & & $\mathrm{~K}_{5}$ & & $\mathrm{~K}_{6}$ & & & \\
\hline & 55 & & 54 & & 42 & & 45 & & 55 & & 45 & & & \\
\hline
\end{tabular}

\subsection{Comparison bet. Conventional and Fuzzy Controller on Multi-Machine System}

\subsubsection{Study Case: Contingency Study Case}

(Outage of line 8-9)

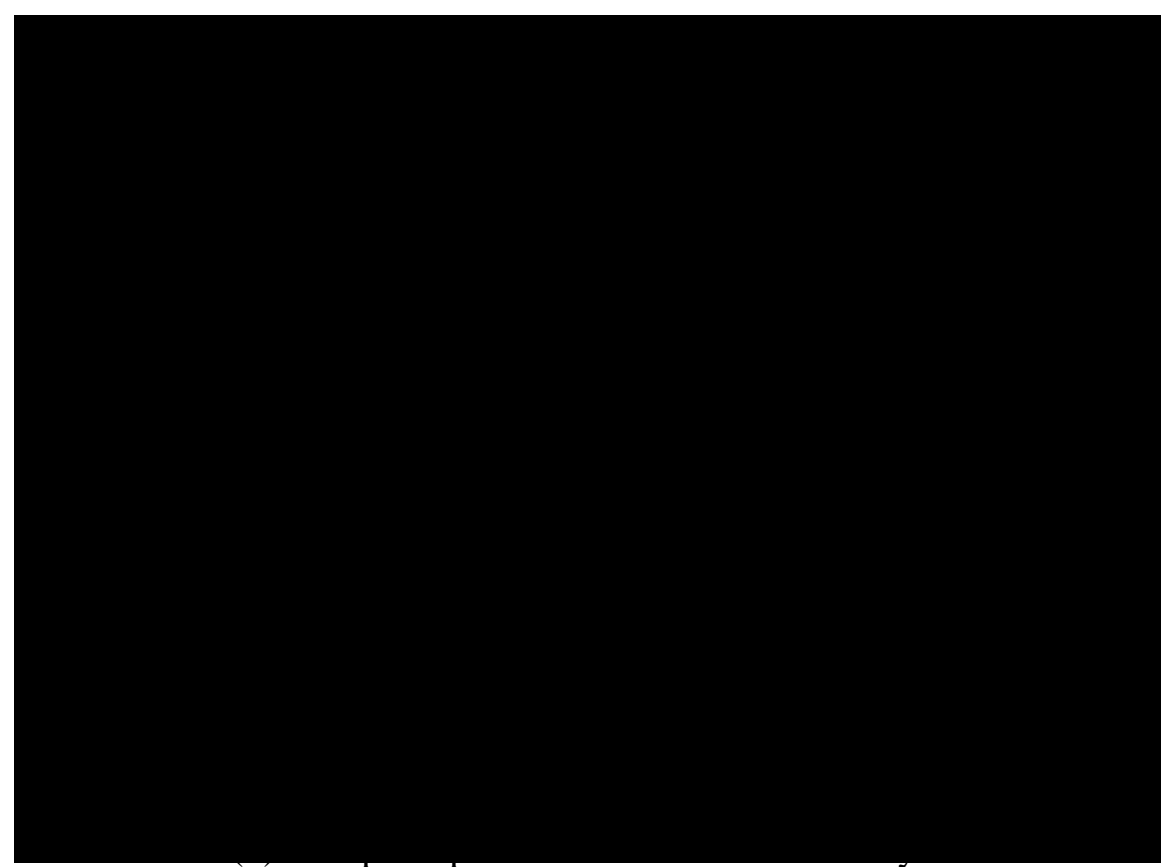

(For increase $10 \%$ in $\Delta \mathrm{Tm} 1$ )

\subsection{Fuzzy Controller based on Participation Analysis}

Using the participation analysis to identify the modes which related to each eigen value by its related state variable, this is important to figure which state variables contribute largely in the system instability by having the least real part of the system eigen values.

The mode identification can be calculated using participation matrix to know which state variable effects strongly in which eigen value how contribute the system instability.

So firstly from the pervious analysis, with the of multi machine system we can get the eigen values of the system as follow 


$$
\left[\begin{array}{l}
\lambda_{1} \\
\lambda_{2} \\
\lambda_{3} \\
\lambda_{4} \\
\lambda_{5} \\
\lambda_{6} \\
\lambda_{7} \\
\lambda_{8} \\
\lambda_{9} \\
\lambda_{10} \\
\lambda_{11} \\
\lambda_{12} \\
\lambda_{13} \\
\lambda_{14} \\
\lambda_{15}
\end{array}\right]=\left[\begin{array}{l}
-216.48 \\
-218.47 \\
-220.91 \\
-0.046877+0.030775 \mathrm{i} \\
-0.046877-0.030775 \mathrm{i} \\
-0.045016+9.0503 \mathrm{i} \\
-0.045016-9.0503 \mathrm{i} \\
-1.4485+0.71405 \mathrm{i} \\
-1.4485-0.71405 \mathrm{i} \\
0.018844+3.0555 \mathrm{i} \\
0.018844-3.0555 \mathrm{i} \\
-2.8551 \\
-1.5586 \\
-0.13216+7.0628 \mathrm{i} \\
-0.13216-7.0628 \mathrm{i}
\end{array}\right]
$$

from the participation matrix and also with comparison the eigen values, we can notice that the most effective eigen values which contribute in system instability are $(\lambda 4, \lambda 5$ $, \lambda 6, \lambda 7, \lambda 10, \lambda 11)$ which related to the mechanical modes of the generator $1,2,3$.

* Mechanical Modes of Generator $1(\Delta \delta 1, \Delta \omega 1)$ : $\quad \lambda 10, \lambda 11$

* Mechanical Modes of Generator2 $(\Delta \delta 2, \Delta \omega 2): \quad \lambda 6, \lambda 7$

* Mechanical Modes of Generator-3( $\Delta \delta 3, \Delta \omega 3)$ : $\quad \lambda 4, \lambda 5$

As mentioned previously that the output of the fuzzy controller reach to the same gains values to get the same response, this can be checked as follow

For same case (Base Case)

*Using All $\lambda: \quad$ K-matrix $=\left[\begin{array}{lllllll}54.6441 & -0.5934 & 10.89 & 1.9967 & 116.45 & 1.0927\end{array}\right]$

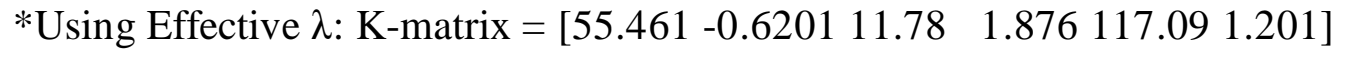

\section{CONCLUSIONS}

This paper presents an effective fuzzy controller which applied on single machine model and multi-machine model and gives an excellently response over wide range of operating conditions comparable with conventional controller which gives unsatisfactory performance in most study cases.

The idea of the controller is extremely new not used before where it depends on reduce all modeling parameters and loading conditions in the eigen values of the system instead of using all the parameters as input which leads to very large number of inputs, specially the input-output patterns are automatic generated using conventional programming. The controller can be combined with load forecast program to supply the controller with predicted loading condition to get the suitable controller feed back gains to keep and enhance the stability of the system.

The fuzzy controller can be considered as power system stabilizer which improves the stability of the system, and it belongs to adaptive control where the fuzzy controller, 
once trained by a set of input-output patterns, can yield proper control action under any operating conditions.

\section{REFERENCES}

[1]N. Hossein zadeh and A. Kalam, "A direct adaptive fuzzy power systems stabilizer,” IEEE Trans. Energy Conversion, vol. 14, pp. 1564-1571, Dec. 1999.

[2] J. Wen, S. Cheng, and O. P. Malik,"A synchronous generator fuzzy Excitation controller optimally designed with a genetic algorithm," IEEE Trans. Power Syst., vol. 13, pp. 884-889, Aug. 1998.

[3] P. Shams ollahi and O. P. Malik, "An adaptive power system stabilizer using online trained neural networks," IEEE Trans. Energy Conversion, vol. 12, pp. 382-387, Dec. 1997.

[4] P. Hoang and K. Tomsovic, "Design and analysis of an adaptive fuzzy power system stabilizer," IEEE Trans. Energy Conversion, vol. 11, pp.455-481, June 1996.

[5] J. Lu, M. H. Nehrir, and D. A. Pierre, "A fuzzy logic-based adaptive power system stabilizer for multi-machine systems," in IEEE Power Eng. Soc. Summer Meeting, Seattle, WA, July 15-19, 2000.

[6] C. T. Tse and S. K. Tso, "Refinement of conventional PSS design in Multi machine system by modal analysis," IEEE Trans. Power Syst., vol 8, pp. 598-605, May 1993. 1994.

[7] S. Mishra, P. K. Dash, P. K. Hota, and M. Tripathy, "Genetically Optimized Neuro-Fuzzy IPFC for Damping Modal Oscillations of Power System", IEEE Transactions On Power Systems, Vol. 17, No. 4, NOVEMBER 2002

[8] Ruhua You, Hassan J. Eghbali, and M. Hashem Nehrir, "An Online Adaptive Neuro-Fuzzy Power System Stabilizer for Multi-machine Systems", IEEE Transactions On Power Systems, Vol. 18, No. 1,,February 2003.

[9] Wenxin Liu*, Ganesh K. Venayagamoorthy and Donald C. Wunsch II, "Design of an adaptive neural network based power system stabilizer", Special issue 2003 (W. Liu et al. / Neural Networks 16 (2003), P. 891-898).

[10] Yannis L. Karnavas, Demetrios P. Papadopoulos, "Excitation Control of A Synchronous Machine Using Polynomial Neural Networks", Journal of Electrical Engineering, Vol. 55, No. 7-8, 2004, P.169-179.

[11] Michael J. Gibbard, David J. Vowles, "Reconciliation of Methods of Compensation for PSSs in Multi-machine Systems", IEEE Transactions on Power Systems, Vol. 19, No. 1, February 2004.

[12] A. Elices, L. Rouco, H. Bourlès and T. Margotin, "Physical Interpretation of State Feedback Controllers to Damp Power System Oscillations", IEEE Transactions on Power Systems, Vol. 19, No. 1, February 2004. 